\title{
A prospective observational study of the epidemiology and pathological profile of RCC in a South African referral centre
}

\author{
D. E. Du Plessis ${ }^{*}$ (1) H. Van Deventer, P. Fernandez and A. Van Der Merwe
}

\begin{abstract}
Background: There are global differences in the incidence, stage, prognosis, pathological profile and presentation of renal cell carcinoma (RCC). We review and describe the risk factors, pathological profile, stage and epidemiology of RCC in a South African centre. Prospective data were collected from all patients undergoing partial or radical nephrectomy for suspected RCC from July 2016 to March 2018.

Results: We collected data from 35 patients and excluded four patients after histological examination showed benign disease. The most common mode of presentation was incidental finding in 48\%; with only one case presenting with the classical triad of abdominal mass, flank pain and macroscopic haematuria. The pathological profile of RCC cases included: clear cell 23 (74\%), papillary type II 5 (16\%), papillary mixed type I and II 1 (3\%) and chromophobe 2 (7\%). The pathological stage of the patients varied, from pT1a to pT3b. The median stage of presentation was pT $1 \mathrm{~b}$. There was a trend towards a more advanced stage with the presence of obesity, female gender, smoking and hypertension.
\end{abstract}

Conclusion: The pathological profile and presenting symptoms in our population mimics that seen in Europe and the USA, with the exception of an increased prevalence of papillary type II RCC. The stage and presenting symptoms differ from that seen in other African studies, whilst our population followed the trend of younger presentation seen elsewhere in Africa.

Keywords: Renal cell carcinoma, Epidemiology, Risk factors, Pathological profile

\section{Background}

Little information exists regarding the epidemiology of renal cell carcinoma (RCC) in South Africa, or Africa [1]. There are global disparities in the incidence of RCC, with a higher incidence in Europe and North America and a lower incidence in Asia and South America [2]. There are also known population group and gender disparities with regards to stage at presentation and prognosis of RCC.

Studies from the USA have shown a significantly increased incidence of RCC and lower associated survival

\footnotetext{
*Correspondence: duplessisdanelo@gmail.com

Department of Urology, Faculty of Health Sciences, University

of Stellenbosch/Tygerberg Campus, P.O. Box 19063, Tygerberg 7505, South Africa
}

rate in African American and Hispanic patients, with poorer survival in African American patients, despite presenting at a younger age and earlier stage $[3,4]$ Possible explanations include socioeconomic factors, increased presence of comorbidities such as hypertension, or genetic factors [4]. Presentation in Africa is typically at a younger age and with a more advanced stage [5, 6].

In recent years, there has been a plateau in the incidence of RCC, after decades of increase [7]. A downward stage migration has occurred to favour smaller, organ confined tumours, likely due to more liberal use of imaging modalities [2]. Incidental discovery is now the most likely presentation of RCC in much of the world, with $82 \%$ of masses less than $4 \mathrm{~cm}$ and $56 \%$ of those greater 
than $6 \mathrm{~cm}$ discovered incidentally [8-10]. In contrast, one study from South Africa reported the median size at presentation as $10 \mathrm{~cm}$, with only $26 \%$ being smaller than $7 \mathrm{~cm}$ (stage T1) [1]. Globally, men have almost double the risk of developing RCC, and also an increased mortality rate from RCC, with females being 19\% less likely to die from the disease [11]. The incidence of RCC steadily increases with age according to the Surveillance, Epidemiology and End Results (SEER) database, peaking between 60 and 70 years, with an impression of declining incidence after 70 years. This might be explained by less aggressive diagnostic pursuit in the elderly [3].

Histologically the most common forms of RCC are clear cell RCC (70-75\%), papillary RCC (10\%) and chromophobe RCC (5\%) [12]. Data from Africa are lacking, but one study from Nigeria showed a marked difference in pathological profile compared to global data, with clear cell (47\%) comprising a much lower proportion of cases than usual, while papillary RCC (30\%) and chromophobe RCC (17\%) were more common than global incidences [5].

There are several defined risk factors for RCC. Smoking is an independent risk factor for RCC, the risk is cumulative and dose dependent [13]. Obesity has been estimated to account for over 30\% of RCC cases in Europe and 40\% of cases in the USA [14]. The hazard ratio for patients with a body mass index (BMI) above $35 \mathrm{~kg} / \mathrm{m}^{2}$ is $1.8 \mathrm{com}$ pared to patients with a normal BMI [15]. Although obesity and hypertension are frequently present in the same patient population, there is evidence that hypertension is an independent risk factor for the development of RCC [16].

This study is the first of its type, designed to give an accurate report on the demographics, stage, pathological profile and risk factors for RCC in a South African centre and to compare the results to global and other African studies. We also evaluated if the presence of known risk factors for RCC translates into a more advanced stage at presentation, or a higher International Society of Urologic Pathologists (ISUP) grade.

\section{Methods}

Prospective data were collected from patients undergoing nephrectomy for suspected RCC at a South African centre from July 2016 to March 2018. Inclusion criteria were all patients older than 18 years due to undergo radical or partial nephrectomy for suspected RCC based on crosssectional imaging. Exclusion criteria were benign indication for nephrectomy or patients younger than 18 years. During the admission process, routine data were collected on the admission form and added to an electronic database by the investigator, after informed consent was taken. Complete data sets were obtained on all patients.
In this report, we present their demographic data, risk factors, staging and pathological data.

\subsection{Statistical analysis}

The patients' clinical and demographic characteristics are summarised (Table 1). Continuous variables were described using the mean and standard deviation, or the median and interquartile range, depending on the distribution of the data. Categorical data were described using frequencies and percentages. A $p$ value of $<0.05$ was considered statistically significant. All statistical calculations were done in Excel.

The five risk factors included in the study: BMI, smoking history, race, gender and hypertension were summarised as well as the pathological staging of each participant, according to the T-stage and the ISUP grade. The risk factors were dichotomised as follows: BMI $<25 \mathrm{~kg} / \mathrm{m}^{2}$ and $\geq 25 \mathrm{~kg} / \mathrm{m}^{2}$; smoking history as yes/no; race as white or mixed ancestry/black; gender as male/ female and hypertension as yes/no and then expressed according to the frequency of the pathological staging in each group (Table 2).

\section{Results}

There were 35 patients who presented with suspected RCC on diagnostic radiology between July 2016 and March 2018. Four patients were excluded due to benign disease (two cases of oncocytoma, one leiomyoma and one echinococcus cyst). Data from the remaining 31 patients are included in this study. There was a male predominance of $18(58 \%)$ to $13(42 \%)$, with a ratio of 1.38:1. The age range of patients was $25-74$ years, with a mean age of 56.39 years (SD 10.16). The racial distribution of patients included: two black patients (6.45\%), 19 mixed ancestry patients $(61.29 \%)$ and ten white patients (32.26\%).

Overweight patients $\left(\mathrm{BMI} \geq 25 \mathrm{~kg} / \mathrm{m}^{2}\right)$ accounted for $65 \%(n=20)$ of our patients with $13(42 \%)$ of them being obese $\left(\mathrm{BMI}>30 \mathrm{~kg} / \mathrm{m}^{2}\right)$. The range of BMI was $18-45 \mathrm{~kg} /$

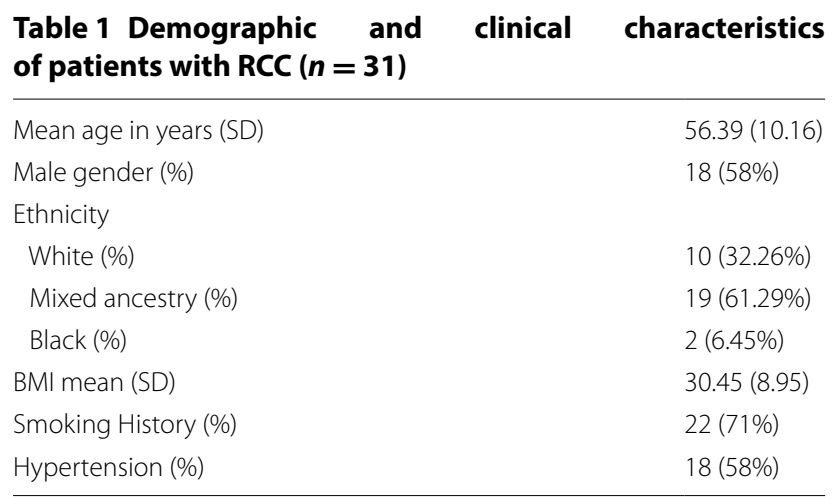


Table 2 Relationship between risk factors and pathological stage and grade

\begin{tabular}{|c|c|c|c|c|}
\hline \multirow{2}{*}{$\begin{array}{l}\text { Risk factor } \\
\mathrm{BMI}\end{array}$} & \multicolumn{2}{|c|}{ Pathological T-stage (median) } & \multicolumn{2}{|c|}{ WHO/ISUP grade } \\
\hline & $<25 \mathrm{~kg} / \mathrm{m}^{2}$ & $\geq 25 \mathrm{~kg} / \mathrm{m}^{2}$ & $<25 \mathrm{~kg} / \mathrm{m} 2$ & $\geq 25 \mathrm{~kg} / \mathrm{m}^{2}$ \\
\hline & $1 b$ & $2 b$ & 2 & 2 \\
\hline \multirow[t]{2}{*}{ Smoking history } & No & Yes & No & Yes \\
\hline & $1 b$ & $2 b$ & 2 & 2 \\
\hline \multirow[t]{2}{*}{ Hypertension } & No & Yes & No & Yes \\
\hline & $1 b$ & $2 \mathrm{a}$ & 2 & 2 \\
\hline \multirow[t]{2}{*}{ Race } & White & Mixed ancestry/Black & White & Mixed ancestry/Black \\
\hline & $2 \mathrm{a}$ & $1 b$ & 2 & 2 \\
\hline \multirow[t]{2}{*}{ Gender } & Female & Male & Female & Male \\
\hline & $2 b$ & $1 b$ & 2 & 2 \\
\hline
\end{tabular}

Table 3 Distribution of RCC pathological subtypes

\begin{tabular}{ll}
\hline Profile of histological subtypes & \\
Clear cell RCC & $23(74 \%)$ \\
Papillary type I & $1(3 \%)$ mixed type I and II \\
Papillary type II & $5(16 \%)$ \\
Chromophobe & $2(7 \%)$ \\
\hline
\end{tabular}

$\mathrm{m}^{2}$ with a mean of $30.45 \mathrm{~kg} / \mathrm{m}^{2}$ (SD 8.95). There was a strong smoking history among our cohort, with 22 (71\%) having a smoking history: current smokers were 16 (52\%) and previous smokers six (19\%). Eighteen (58\%) patients were known to suffer from hypertension. We did not have any patients who had either a family history of RCC, or a suspected hereditary form of RCC in this cohort.

The pathological profile of our cases included: clear cell 23 (74\%), papillary type II: 5(16\%), papillary mixed type I and II: 1 (3\%) and chromophobe 2 (7\%). See Table 3.

The most common presentation was incidental finding in 15 (55\%) patients. Of the symptomatic patients, seven (16\%) experienced flank pain and seven (16\%) experienced macroscopic haematuria. These were the most common symptoms. Only one (4\%) of our patients had the classical triad of flank mass, macroscopic haematuria and pain.

The pathological stage of the patients varied, from $\mathrm{pT} 1 \mathrm{a}$ to $\mathrm{pT} 3 \mathrm{~b}$. The most frequent stage of presentation was pT1b. There was a trend towards a more advanced stage with the presence of obesity, smoking and hypertension. Of note was the higher stage of presentation of females in the study population. See Table 2.

\section{Discussion}

The mean age of our study population was 56 years, which is younger than that reported in data from the USA and Europe, where the incidence peaks in the seventh decade, but not as young as in the rest of the African continent, where mean age of presentation is typically in the fifth decade [5]. This trend continues in the USA, where African American patients tend to present at a younger age [4]. The reason for this earlier presentation is likely multifactorial and includes genetic, environmental and epidemiological factors.

Our gender and pathological profile closely mimics that described in the literature [7, 12]. An exception to this is the relatively high incidence of papillary Type II RCC compared to Type I. Our pathological profile also differed markedly from that seen in the aforementioned study from Nigeria [5]. Larger studies will need to confirm this finding, which might be due to underlying genetic differences or environmental factors in our population. The racial distribution in this study cannot be extrapolated to denote incidence among the various racial groups, due to wide variability in local referral and healthcare systems.

We demonstrated that known risk factors for RCC such as obesity, smoking and hypertension were also present within our population and compared their prevalence to that found in the general population of the Western Cape and South Africa. The median BMI in the baseline South African population is $25.18 \mathrm{~kg} / \mathrm{m}^{2}$, with $28.1 \%$ being obese [17]. Our study population had a higher mean BMI of $30.45 \mathrm{~kg} / \mathrm{m}^{2}$, with $42 \%$ ( $\left.n=13\right)$ being obese. The prevalence of smoking in our study population was $71 \%(n=22)$, of which current smokers made up $52 \%$ and previous smokers $19 \%$. This is higher than the $32.9 \%$ prevalence of smoking in the general population of the Western Cape [18]. We also demonstrated a higher prevalence of hypertension of $58 \%(n=18)$ in our study, compared to the known $19.8 \%$ prevalence of hypertension in the general population of South Africa [19].

The most common mode of presentation was incidental finding on imaging (55\%). Our median stage of 
presentation was $\mathrm{pT} 1 \mathrm{~b}$. This is in keeping with that seen in Europe and the USA where $58-89 \%$ of tumours are $<7 \mathrm{~cm}$ (pT1) [20]. It is a lower stage compared to data in the rest of Africa, where RCC tends to present at a more advanced stage $[5,6]$. This may reflect differences in access to healthcare and imaging, but further studies to define genetic and tumour characteristics in African populations are needed.

In our population, obesity, smoking history, hypertension and female gender were more prevalent in patients with advanced tumour stage at presentation. This can be explained by the oncogenic mechanisms such as chronic tissue hypoxia, reactive oxygen species, endothelial dysfunction, hyper inflammatory state and toxins, which might enhance tumour growth velocity [13, 21, 22]. The association of female gender with a more advanced tumour stage at presentation was unexpected and cannot be explained solely by aforementioned oncogenic mechanisms. There was a weak association between the presence of hypertension and a more advanced tumour stage. We could not demonstrate a higher WHO/ISUP grade when oncological risk factors such as smoking, hypertension or obesity were present.

\subsection{Limitations}

Our study was limited by the small sample size and the fact that we did not include patients whom did not have a histological diagnosis. However, the only other South African study was retrospective and lacked sufficient data to adequately assess for the presence of risk factors [1].

\section{Conclusion}

Our study demonstrated that smoking, obesity, female gender and hypertension were more prevalent in patients with a more advanced stage at presentation. The pathological profile and presenting symptoms in our population mimics that seen in Europe and USA, but differs from that seen in other African studies. However, patients in our study followed the trend of African patients to present at a younger age, although only two of our patients were black. This highlights the complex interaction between genetic and environmental factors at play.

\section{Abbreviations}

BMI: Body mass index; ISUP: International Society of Urologic Pathologists; RCC : Renal cell carcinoma; SD: Standard deviation; SEER: Surveillance, epidemiology and end results.

\section{Acknowledgements}

Not applicable.

\section{Authors' contributions}

DEdP was responsible for the data collection and writing up of the manuscript; HvD assisted with the writing up of the manuscript; PF assisted with the writing up of the manuscript; AvdM assisted with the writing up of the manuscript. All authors read and approved the final manuscript.

\section{Funding}

No external funding was received for the research; departmental funds were used.

\section{Availability of data and materials}

The datasets used and analysed during the current study is available from the corresponding author on reasonable request.

\section{Ethics approval and consent to participate}

Ethical clearance was obtained from the Health Research Ethics Committee of the University of Stellenbosch, ethics reference S16/07/118. Written informed consent was obtained from the participants.

\section{Consent for publication}

Not applicable.

\section{Competing interests}

The authors declare that they have no competing interests.

Received: 11 November 2019 Accepted: 28 January 2020

Published online: 01 April 2020

\section{References}

1. Singh A, Urry RJ, Hardcastle TC (2018) Five year review of open radical nephrectomies at a regional hospital in South Africa: room for improvement. S Afr J Surg. 56(1):35-39

2. Curado M, Edwards B, Shin H, Storm H, Ferlay J, Heanue M, et al. Cancer incidence in five continents, Volume IX. In Curado M, Edwards B, Shin H, Storm H, Ferlay J, Heanue M, et al., editors. IARC Scientific Publication No. 160; 2007. p. 744-751. Available from disparities in the publications.iarc.fr/ Book-And-Report-Series/larc-Scientific-Publications/Cancer-Incidence-InFive-Countries-Volume-IX-2007

3. Chow W-H, Devesa SS (2008) Contemporary epidemiology of renal cell cancer. Cancer J 14(5):288-301

4. Patel HD, Kates M, Pierorazio PM, Allaf ME (2014) Race and sex disparities in the treatment of older patients with T1a renal cell carcinoma: a comorbidity-controlled competing-risks model. Urol Oncol. 32(5):576-583

5. Akinfenwa AT, Jareenat AO, Noah DT. Histological and immunohistochemically profiles of renal cell carcinoma in northern Nigeria. Immunopathol Persa. 2018;4(1). Available from: http://immunopathol.com/PDF/ ipp-4-e12.pdf?t=636532700955055660

6. Takure AO, Shittu OB, Adebayo SA, Okolo CA, Sotunmbi PT (2013) Renal cell carcinoma in Ibadan: a 5-year clinicopathologic review. Afr J Med Med Sci 42(3):239-243

7. Chow W-H, Dong LM, Devesa SS (2010) Epidemiology and risk factors for kidney cancer. Nat Rev Urol. 7(5):245-257

8. Sánchez-Martín FM, Millán-Rodríguez F, Urdaneta-Pignalosa G, Rubio-Briones J, Villavicencio-Mavrich H (2008) Small renal masses: incidental diagnosis, clinical symptoms, and prognostic factors. Adv Urol. 2008:310694

9. Kane CJ, Mallin K, Ritchey J, Cooperberg MR, Carroll PR (2008) Renal cell cancer stage migration. Cancer 113(1):78-83

10. Volpe A, Panzarella T, Rendon RA, Haider MA, Kondylis FI, Jewett MAS (2004) The natural history of incidentally detected small renal masses. Cancer 100(4):738-745

11. Rampersaud EN, Klatte T, Bass G, Patard J-J, Bensaleh K, Böhm M et al (2014) The effect of gender and age on kidney cancer survival: younger age is an independent prognostic factor in women with renal cell carcinoma. Urol Oncol. 32(1):30.e9-30.e13

12. Lopez-Beltran A, Scarpelli M, Montironi R, Kirkali Z (2006) 2004 WHO classification of the renal tumors of the adults. Eur Urol 49(5):798-805

13. Tsivian M, Moreira DM, Caso JR, Mouraviev V, Polascik TJ (2011) Cigarette smoking is associated with advanced renal cell carcinoma. J Clin Oncol 29(15):2027-2031 
14. Oh SW, Yoon YS, Shin S-A (2005) Effects of excess weight on cancer incidences depending on cancer sites and histologic findings among men: Korea National Health Insurance Corporation Study. J Clin Oncol 23(21):4742-4754

15. Häggström C, Rapp K, Stocks T, Manjer J, Bjørge T, Ulmer H et al (2013) Metabolic factors associated with risk of renal cell carcinoma. PLoS ONE 8(2):e57475 (Miller TW, editor)

16. Chow W-H, Gridley G, Fraumeni JF, Järvholm B (2000) Obesity, hypertension, and the risk of kidney cancer in men. N Engl J Med 343(18):1305-1311

17. Cois A, Day C (2015) Obesity trends and risk factors in the South African adult population. BMC Obes. 2(1):1-10. https://doi.org/10.1186/s4060 8-015-0072-2

18. Reddy P, Zuma K, Shisana O, Kim J, Sewpaul R (2015) Prevalence of tobacco use among adults in South Africa: results from the first South African National Health and Nutrition Examination Survey. S Afr Med J. 105(8):648

19. Stringhini S, Forrester TE, Plange-Rhule J, Lambert EV, Viswanathan B, Riesen W et al (2016) The social patterning of risk factors for noncommunicable diseases in five countries: evidence from the modeling the epidemiologic transition study (METS). BMC Public Health 16(1):1-10. https://doi.org/10.1186/s12889-016-3589-5

20. Hafez KS, Fergany AF, Novick AC (1999) Nephron sparing surgery for localized renal cell carcinoma: impact of tumor size on patient survival, tumor recurrence and TNM staging. J Urol 162(6):1930-1933

21. Orth SR (2002) Cigarette smoking: an important renal risk factor-far beyond carcinogenesis. Tob Induc Dis. 1(2):137-155

22. Gago-Dominguez M, Castelao JE, Yuan J-M, Ross RK, Yu MC (2002) Lipid peroxidation: a novel and unifying concept of the etiology of renal cell carcinoma (United States). Cancer Causes Control 13(3):287-293

\section{Publisher's Note}

Springer Nature remains neutral with regard to jurisdictional claims in published maps and institutional affiliations.

\section{Submit your manuscript to a SpringerOpen ${ }^{\odot}$ journal and benefit from:}

- Convenient online submission

- Rigorous peer review

- Open access: articles freely available online

- High visibility within the field

- Retaining the copyright to your article

Submit your next manuscript at $\boldsymbol{\nabla}$ springeropen.com 